\title{
AÇÃo de Herbicidas SOBRE MiCRORGanismos SOlUbilizadores DE Fosfato Inorgânico em Solo RIZOSFÉrico de CANA-DE-AÇÚCAR ${ }^{1}$
}

\author{
Action of Herbicides on Inorganic Phosphate-Solubilizing Microorganisms in Sugarcane \\ Rhizospheric Soil
}
REIS, M. R. ${ }^{2}$; SILVA, A. A. ${ }^{3}$; GUIMARÃES, A. A. ${ }^{4}$; COSTA, M. D. ${ }^{5}$ MASSENSSINI, A. M. ${ }^{6}$; FERREIRA, E. A. ${ }^{7}$

\begin{abstract}
RESUMO - Objetivou-se avaliar, com este trabalho, o impacto dos herbicidas ametryn e trifloxysulfuron-sodium, isolados ou em mistura, e 2,4-D na atividade dos microrganismos solubilizadores de fosfato inorgânico e a densidade populacional de bactérias e fungos do solo rizosférico de cana-de-açúcar. Plantas de cana-de-açúcar com três a quatro folhas completamente expandidas foram aspergidas com soluções de 2,4-D, ametryn, trifloxysulfuron-sodium e ametryn+trifloxysulfuron-sodium nas doses de 1,30; 1,00; 0,0225; e 1,463+0,0375 $\mathrm{kg} \mathrm{ha}^{-1}$, respectivamente. Utilizou-se o delineamento inteiramente casualizado no esquema de parcelas subdivididas, com quatro repetições. Nas parcelas foram avaliados os efeitos dos herbicidas e, nas subparcelas, o efeito tempo após a aplicação dos herbicidas. Aos 15, 30, 45 e 60 dias após a aplicação (DAA), amostras de solos rizosférico e não-rizosférico foram coletadas e, em seguida, analisadas estimando-se a densidade populacional de bactérias e fungos, a atividade potencial de solubilização de fosfato inorgânico e a solubilização relativa de fosfato inorgânico. O 2,4-D reduziu a densidade populacional bacteriana do solo em todas as épocas de avaliação, demonstrando a maior sensibilidade desse grupo de organismos a esse composto. Todos os herbicidas provocaram redução na densidade populacional fúngica do solo somente aos 15 DAA. O trifloxysulfuron-sodium e o 2,4-D favoreceram as maiores atividades de solubilização de fosfato inorgânico aos 15, 30 e 45 DAA e aos 15 e 30 DAA, respectivamente, sem, no entanto, afetar a biomassa microbiana do solo. Maior solubilização relativa de fosfato inorgânico foi observada em amostras de solos tratados com a mistura ametryn+trifloxysulfuron-sodium, indicando alterações no sistema solo. Este trabalho evidenciou que a aplicação dos herbicidas na parte aérea de plantas de cana-de-açúcar afetou o número de microrganismos e a atividade de solubilização de fosfato na rizosfera.
\end{abstract}

Palavras-chave: bactérias, fungos, ametryn, trifloxysulfuron-sodium, 2,4-D.

\begin{abstract}
The objective of this work was to evaluate the impact of the herbicides ametryn and trifloxysulfuron-sodium, singly or combined, and 2,4-D, on the activity of inorganic phosphatesolubilizing microorganisms and the populational density of fungi and bacteria in sugarcane rhizosphere. Sugarcane plants with three to four fully expanded leaves and fungi were sprayed with ametryn, trifloxysulfuron-sodium, and ametryn + trifloxysulfuron-sodium at the doses of $1.30,1.00,0.0225$ and $1.463+0.0375 \mathrm{~kg} \mathrm{ha}^{-1}$, respectively. A completely randomized design was adopted in a split plot scheme with four replications. The effect of the herbicides was evaluated in the whole plots and the effect of time after application in the split-plots. At 15, 30, 45, and 60 days after spraying (DAS), rhizospheric and non-rhizospheric soil samples were collected and immediately analyzed for the populational densities of bacteria and fungi and the potential and relative inorganic phosphate solubilization activity in the soil. 2, 4-D reduced the bacterial density
\end{abstract}

1 Recebido para publicação em 13.4.2007 e na forma revisada em 29.1.2008.

2 Engo-Agró-, Estudante de Doutorado do Dep. de Fitotecnia, Bolsista do CNPq, Universidade Federal de Viçosa - UFV, 36570000, Viçosa-MG<reisagro@yahoo.com.br>. ${ }^{3}$ D.S., Professor Associado do Dep. de Fitotecnia - UFV; ${ }^{4}$ Graduanda em Agronomia, Bolsista de Iniciação Científica/CNPq - UFV; ${ }^{5}$ D.S., Professor Associado do Dep. de Microbiologia - UFV; ${ }^{6}$ Biólogo, Mestre em Microbiologia Agrícola - UFV; ${ }^{7}$ Engenheiro Agrônomo, Doutor em Fitotecnia - UFV.

Planta Daninha, Viçosa-MG, v. 26, n. 2, p. 333-341, 2008 
in the soil for all the evaluation times, densities of bacterial populations in the rhizosphere for all periods of time showing a higher sensitivity of this group to this compound. At 15 DAS, all herbicides tested reduced the number of fungi in the soil. Trifloxysulfuron-sodium and 2, 4-D led to higher inorganic phosphate solubilization at 15, 30, and 45 DAS, and 15 and 30 DAS, respectively, without affecting microbial biomass. The highest relative inorganic phosphate solubilization was observed in the soils treated with ametryn + trifloxysulfuron-sodium. This work showed that herbicide application on sugarcane shoots affects the number of microorganisms and phosphate solubilization activity in the rhizosphere.

Keywords: bacteria, fungi, ametryn, trifloxysulfuron-sodium, 2,4-D.

\section{INTRODUÇÃO}

A utilização de grandes áreas e quantidades expressivas de insumos agrícolas pode afetar a qualidade do solo, sendo as práticas utilizadas questionadas pela comunidade cientifica quanto à sustentabilidade dos agroecossistemas. O termo qualidade do solo relaciona-se às propriedades biológicas, físicas e químicas do solo - essenciais para manter a produtividade agrícola a longo prazo e com o mínimo de impacto negativo possivel (Tótola \& Chaer, 2002). Algumas propriedades biológicas do solo "enfatizando as de natureza microbiológica" têm sido propostas como as mais sensiveis a mudanças quando os solos são submetidos a diferentes tipos de manejo e, portanto, seriam mais adequadas como indicadores de qualidade do solo (Pankhurst et al., 1997; Tótola \& Chaer, 2002). Segundo Bottomley (2005), os microrganismos do solo influenciam diretamente a fertilidade e a produtividade vegetal por meio da ciclagem de nutrientes, supressão de fitopatógenos, produção de fitormônios e, ainda, a capacidade de metabolização de agrotóxicos. Também, Das et al. (2003) e Tótola $\&$ Chaer (2002) enfatizaram que as atividades dos microrganismos estão envolvidas no ciclo biogeoquímico, visto que influenciam diretamente a disponibilidade dos nutrientes e elucidam melhor as mudanças do funcionamento do ecossistema solo.

Apesar de presente em grande quantidade no solo, o nutriente fósforo (P) é encontrado em baixíssimas concentrações na solução do solo (0,1 a $1,0 \mathrm{mg} \mathrm{L}^{-1}$ de $\left.\mathrm{H}_{2} \mathrm{PO}_{4}^{-}\right)$, sendo, portanto, considerado o nutriente mais crítico para todas as formas de vida, por ser constituinte de importantes biomoléculas, como DNA, ATP e fosfolipídios (Novais \& Smyth, 1999).
A dinâmica do $\mathrm{P}$ em solos é complexa devido à ocorrência do fenômeno de retenção de $\mathrm{P}$, isto é, a transformação de P-lábil em $\mathrm{P}$ nãolábil, decorrente da adsorção deste nutriente nos oxidróxidos de $\mathrm{Fe}$ e $\mathrm{Al}$. A retenção de $\mathrm{P}$ também se dá pela sua precipitação com $\mathrm{Fe}$ e Al em solos ácidos e com Ca em solos alcalinos. Dessa forma, a disponibilidade de Pi na solução do solo e a eficiência da adubação fosfatada são reduzidas em solos tropicais, que geralmente apresentam altos teores de oxidróxidos de $\mathrm{Fe}$ e $\mathrm{Al}$ e alta atividade de $\mathrm{Al}^{3+}$ na solução do solo (Novais \& Smyth, 1999). Para redisponibilização do $\mathrm{P}$ precipitado ( $\mathrm{P}-\mathrm{Fe}, \mathrm{P}-\mathrm{Al}$ e $\mathrm{P}-\mathrm{Ca}$ ), plantas e microrganismos acidificam naturalmente o solo rizosférico por meio da liberação de prótons e ácidos orgânicos, sendo os microrganismos denominados de solubilizadores de fosfato inorgânico (MSFI) (Novais \& Smyth, 1999; Rodríguez \& Fraga, 1999). Os MSFI são responsáveis pela liberação de ácidos orgânicos, como o glucônico, cítrico, glutâmico, oxálico, lático, fumárico, tartárico e succínico, os quais atuam como doadores de prótons e agentes quelantes dos íons $\mathrm{Ca}, \mathrm{Al}$ e Fe, favorecendo a solubilização do fosfato inorgânico do solo (Rodríguez \& Fraga, 1999). Os MSFI constituem cerca de 5 a $10 \%$ da microbiota total dos solos e são encontrados na maioria destes. A diversidade e as populações dos MSFI são consideravelmente superiores em solos circunvizinhos às raízes das plantas, ou seja, solos rizosféricos (Nahas et al., 1994; Nautiyal, 1999).

Dentre os MSFI, as bactérias se destacam com o maior potencial de utilização para obtenção de fosfatos solúveis a partir da solubilização biológica de fosfatos e como inoculantes para as culturas. Os principais gêneros bacterianos: Pseudomonas, Bacillus, Rhizobium, Burkholderia, Achromobacter, Microccocus, 
Aereobacter e Flavobacterium (Rodríguez \& Fraga, 1999) são hábeis na solubilização de fosfato inorgânico, promovendo o crescimento de plantas pela exsudação de fitormônios, vitaminas e antibióticos. Além disso, a população e a atividade dos MSFI estão relacionadas com o manejo e tipo do solo, sendo considerados indicadores microbiológicos associados ao ciclo do P no solo (Kucey, 1983; Nahas et al., 1994; Carneiro et al., 2004) e contribuindo na adoção de práticas agrícolas menos impactantes ao ambiente. No entanto, no Brasil não há estudos que evidenciam possiveis impactos da aplicação de herbicidas sob a dinâmica dos MSFI do solo.

Entre os estudos realizados, Rosas et al. (2006) indicaram que a dupla inoculação com Bradyrhizobium japonicum (fixadores de N) e Pseudomonas putida (solubilizadoras de Pi) em plantios de soja aumentou o número e a massa seca dos nódulos radiculares, demonstrando a possivel influência dos MSFI na interação leguminosa-rizóbio. No entanto, outros trabalhos demonstraram que alguns agrotóxicos empregados no manejo fitossanitário de cultivos agrícolas podem interferir na dinâmica populacional e atividade dos MSFI (Congregado et al., 1979; Selvamani \& Sankaran, 1993; Das \& Mukherjee, 1998; Debnath et al., 2002; López et al., 2002; Das et al., 2003).

Em face do exposto, neste trabalho objetivou-se avaliar o impacto dos herbicidas ametryn e trifloxysulfuron-sodium, isolados e em mistura, e também do 2,4-D na atividade e dinâmica populacional dos microrganismos solubilizadores de fosfato inorgânico (MSFI) e totais do solo rizosférico da cultura de cana-de-açúcar.

\section{MATERIAL E MÉTODOS}

O experimento foi conduzido em casa de vegetação pertencente ao Departamento de Fitotecnia da Universidade Federal de ViçosaUFV e no Laboratório de Associações Micorrizicas do Departamento de Microbiologia/ BIOAGRO/UFV, Viçosa, MG.

O substrato utilizado foi o Latossolo Vermelho-Amarelo, extraído do horizonte B do perfil do solo de área sem histórico de aplicação de agrotóxicos. Para cultivo da cana-de-açúcar, utilizaram-se vasos pretos de PVC, revestidos com filme de polietileno e preenchidos com $10 \mathrm{~L}$ de substrato. O substrato foi corrigido com calcário dolomítico $\left(0,15 \mathrm{~g} \mathrm{dm}^{-3}\right)$ e adubado com os fertilizantes: sulfato de amônio $\left(0,09 \mathrm{~g} \mathrm{dm}^{-3} \mathrm{de} \mathrm{N}\right)$, superfosfato simples $\left(1,8 \mathrm{~g} \mathrm{dm}^{-3}\right.$ de $\left.\mathrm{P}_{2} \mathrm{O}_{5}\right)$ e cloreto de potássio $\left(0,34 \mathrm{~g} \mathrm{dm}^{-3} \mathrm{de}_{2} \mathrm{O}\right)$. Posteriormente à correção e adubação, o substrato foi analisado física e quimicamente (Tabela 1). O material propagativo de cana-de-açúcar constituiu-se de segmentos de colmos (tolete contendo uma gema) da variedade RB867515, sendo plantados dois toletes por vaso. Foram também realizadas adubações de cobertura com $100 \mathrm{~mL}$ de solução nutritiva, contendo adubo Ouro Verde ${ }^{\circledR}, \mathrm{N}$ e $\mathrm{K}_{2} \mathrm{O}$ nas concentrações de 10,8 e 23,2 $\mathrm{g} \mathrm{L}^{-1}$, respectivamente, aos 49 e 64 dias após o plantio.

As unidades experimentais foram representadas pelo sistema solo-cana. Utilizou-se o delineamento inteiramente casualizado em esquema de parcelas subdivididas; nas parcelas foram avaliados os efeitos dos herbicidas e, nas subparcelas, o efeito do tempo após a aplicação dos herbicidas, com quatro repetições.

Quando as plantas de cana-de-açúcar se encontravam com três a quatro folhas expandidas, as unidades experimentais foram aspergidas com solução dos herbicidas 2,4-D, ametryn, trifloxysulfuron-sodium e ametryn+ trifloxysulfuron-sodium com concentrações equivalentes às doses de 1,$30 ; 1,00 ; 0,0225$; e $1,463+0,0375 \mathrm{~kg} \mathrm{ha}^{-1}$, respectivamente, utilizando-se pulverizador calibrado para aplicação de $150 \mathrm{~L} \mathrm{ha}^{-1}$ de calda.

Aos 15, 30, 45 e 60 dias após a aplicação (DAA) das soluções herbicidas, amostras de solos rizosférico e não rizosférico foram coletadas. A coleta do solo não-rizosférico foi realizada nas unidades experimentais sem presença de plantas. Para a coleta do solo rizosférico, retirou-se a planta+solo e agitou-se de modo que permanecesse somente o solo firmemente aderido às raízes (solo rizosférico); em seguida, agitou-se novamente, a fim de coletá-lo. As amostras foram imediatamente analisadas, estimando-se a densidade populacional de bactérias e fungos, a atividade potencial de solubilização de fosfato inorgânico e o carbono da biomassa microbiana do solo. A umidade do solo 
Tabela 1 - Características físico-químicas do solo Latossolo Vermelho-Amarelo utilizado no experimento, após calagem e adubação. Viçosa-MG, 2007

\begin{tabular}{|c|c|c|c|c|c|c|c|c|c|c|}
\hline \multicolumn{11}{|c|}{ Análise granulométrica $\left(\mathrm{dag} \mathrm{kg}^{-1}\right)$} \\
\hline Argila & \multicolumn{3}{|c|}{ Silte } & \multicolumn{2}{|c|}{ Areia fina } & \multicolumn{2}{|c|}{ Areia grossa } & \multicolumn{3}{|c|}{ Classe textural } \\
\hline 36 & \multicolumn{2}{|r|}{5} & & \multicolumn{2}{|c|}{10} & \multicolumn{2}{|c|}{49} & \multicolumn{3}{|c|}{ Argilo-Arenosa } \\
\hline \multicolumn{11}{|c|}{ Análise química } \\
\hline $\mathrm{pH}$ & $\mathrm{P}$ & $\mathrm{K}^{+}$ & $\mathrm{H}+\mathrm{Al}$ & $\mathrm{Al}^{3+}$ & $\mathrm{Ca}^{2+}$ & $\mathrm{Mg}^{2+}$ & $\mathrm{T}$ & & $\mathrm{m}$ & $\mathrm{MO}$ \\
\hline $\mathrm{H}_{2} \mathrm{O}$ & \multicolumn{2}{|c|}{$\mathrm{mg} \mathrm{dm}^{-3}$} & \multicolumn{5}{|c|}{ 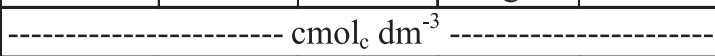 } & \multicolumn{2}{|c|}{$\%$} & dag kg ${ }^{-1}$ \\
\hline 5,6 & 29,5 & 116,0 & 5,28 & 0,0 & 6,20 & 0,80 & 12,58 & 58,0 & 0 & 2,18 \\
\hline
\end{tabular}

Análises realizadas nos Laboratórios de Análises Físicas e Químicas de Solo do Departamento de Solos da UFV.

foi determinada, para posterior conversão dos dados obtidos em base de solo seco.

Para estimativa de densidade populacional de microrganismos do solo, adotou-se o método de contagem de células viáveis em placas. Para isso, pesaram-se $10 \mathrm{~g}$ de solo e transferiuse para garrafas de diluição contendo $90 \mathrm{~mL}$ de solução salina estéril $(0,85 \%$ de $\mathrm{NaCl})$. A suspensão de solo foi agitada manualmente por um minuto. Desse modo, obteve-se a diluição $10^{-1}$. Para as demais diluições $\left(10^{-2}, 10^{-3}, 10^{-4}\right.$ e $10^{-5}$ ), transferiu-se sucessivamente $1 \mathrm{~mL}$ da diluição anterior para tubo de ensaio contendo $9 \mathrm{~mL}$ de solução salina estéril $(0,85 \%$ de $\mathrm{NaCl})$.

Para cada litro de meio de cultura utilizado para crescimento seletivo de fungos e de bactérias, foram adicionados $50 \mathrm{~mL}$ da solução estéril de $\mathrm{KHPO}_{4}\left(100 \mathrm{~g} \mathrm{~L}^{-1}\right)$ e $100 \mathrm{~mL}$ da solução estéril de $\mathrm{CaCl}_{2}\left(100 \mathrm{~g} \mathrm{~L}^{-1}\right)$ para formação de fosfato inorgânico insolúvel $\left(\mathrm{CaHPO}_{4}\right)$ de coloração branco-leitosa, permitindo a contagem dos microrganismos capazes de solubilizar fosfato inorgânico pela formação de halo transparente ao redor de suas colônias. Os isolados bacterianos capazes de solubilizar fosfato inorgânico foram isolados, reisolados e adicionados à coleção de bactérias solubilizadoras de fosfato inorgânico do Laboratório de Associações Micorrízicas/BIOAGRO/UFV, para posterior identificação, caracterização e testes de sensibilidade in vitro a herbicidas.

Para contagem de células bacterianas, foram utilizadas placas de Petri contendo $20 \mathrm{~mL}$ de meio de cultura Glicose-Extrato de Levedura (GEL), pH 5,60, composto pelos seguintes reagentes $\left(\mathrm{g} \mathrm{L}^{-1}\right)$ : glicose, 10,00; extrato de levedura, 2,00; ágar, 15,00; e cicloeximida, 0,02. Em condições assépticas, as placas de Petri foram inoculadas com alíquotas de $0,1 \mathrm{~mL}$ das diluições $10^{-3}, 10^{-4}$ e $10^{-5}$, incubadas por sete dias a $27^{\circ} \mathrm{C}$, procedendo-se a contagens diárias do número de unidades formadoras de colônia (UFC).

Na contagem da população fúngica foi utilizado o meio de cultura Martin, pH 5,60, composto pelos seguintes ingredientes $\left(\mathrm{g} \mathrm{L}^{-1}\right)$ : glicose, 10,00; peptona, 5,00; $\mathrm{KH}_{2} \mathrm{PO}_{4}, 1,00 ; \mathrm{MgSO}_{4}$, 0,50; Rosa Bengala, 0,03; ágar, 15,00; e estreptomicina, 0,02 (Martin, 1950). As diluições utilizadas para o plaqueamento foram $10^{-2}, 10^{-3} \mathrm{e}$ $10^{-4}$, sendo utilizado o procedimento anteriormente descrito para a contagem de células bacterianas.

Para estimativa do potencial da atividade solubilizadora de fosfato inorgânico em meio líquido, transferiu-se $1 \mathrm{~g}$ de solo das amostras de cada repetição para tubo de ensaio com meio líquido NBRI, pH 6,8-7,0, contendo $\left(\mathrm{g} \mathrm{L}^{-1}\right)$ : glicose, 10; $\mathrm{Ca}_{3}\left(\mathrm{PO}_{4}\right)_{2}, 5 ; \mathrm{MgCl}_{2} \cdot 6 \mathrm{H}_{2} \mathrm{O}, 0,5$; $\mathrm{MgSO}_{4} \cdot 7 \mathrm{H}_{2} \mathrm{O}, 0,25 ; \mathrm{KCl}, 0,2$; e $\left(\mathrm{NH}_{4}\right)_{2} \mathrm{SO}_{4}, 0,1$ (Nautyal, 1999). Após incubação por 15 dias a $27^{\circ} \mathrm{C}$, a fase líquida foi submetida à centrifugação a $8.000 \mathrm{rpm}$ por $20 \mathrm{~min}$ e determinou-se no sobrenadante a quantidade de $\mathrm{P}$ inorgânico pelo método colorimétrico da vitamina $\mathrm{C}$ modificado, a 725 nm (Braga \& Defelipo, 1974).

Desenvolveu-se o quociente para avaliação da eficiência da atividade de solubilização de fosfato inorgânico, o qual indica a quantidade de $\mathrm{P}$ inorgânico liberada por unidade de biomassa microbiana do solo, denominada de solubilização relativa de fosfato inorgânico. $\mathrm{Na}$ 
determinação da biomassa microbiana, utilizou-se o método descrito por Vance et al. (1987), modificado por Islam \& Weil (1998), no qual a fumigação do solo com clorofórmio foi substituída pela irradiação de microondas.

Para interpretação dos resultados, após a análise de variância a 5\% de significância, utilizou-se o critério de agrupamento de médias Scott-Knott, para fatores qualitativos, e a análise de regressão, para os fatores quantitativos. A escolha do modelo foi baseada na sua significância e no coeficiente de determinação. Posteriormente, os modelos foram submetidos ao teste de identidade de modelos, comparando-os isoladamente com o modelo-testemunha (solo rizosférico sem aplicação de herbicidas) (Regazzi, 1993).

\section{RESULTADOS E DISCUSSÃO}

As densidades populacionais bacterianas e fúngicas do solo rizosférico (SR) sem aplicação de herbicidas foram superiores às observadas no solo não-rizosférico (SNR), sendo esse fenômeno conhecido como efeito rizosférico (Tabela 2). Esse efeito relaciona-se com a exsudação radicular de compostos orgânicos, a exemplo de aminoácidos, ácidos orgânicos, açúcares e vários outros metabólitos secundários, que representam de 5 a $21 \%$ do total do carbono fixado fotossinteticamente pela planta. Esses exsudatos são considerados fonte de energia e nutrientes, que proporcionam maior metabolismo e crescimento de microrganismos (Marschner, 1995; Walker et al., 2003).

Quanto ao efeito dos herbicidas sobre a microbiota do solo, o 2,4-D reduziu a densidade populacional bacteriana em todas as épocas de avaliação $(15,30,45$ e 60 DAA), demonstrando efeito negativo nas bactérias do solo (Tabela 2). Segundo Thill (2003), o 2,4-D interfere na RNA-polimerase de vegetais, com conseqüentes alterações no metabolismo dos ácidos nucléicos e das proteínas. No entanto, o mecanismo de inibição das populações bacterianas do solo é desconhecido.

Após 30 DAA, a mistura comercial ametryn+trifloxysulfuron-sodium causou redução na densidade populacional de bactérias do solo em relação aos compostos isolados (Tabela 2), enfatizando o efeito sinérgico da mistura ou a
Tabela 2 - Densidade populacional de bactérias e fungos do solo obtidos a partir da contagem de células viáveis de amostras de solo não-rizosférico (SNRSH) e de solos tratados com ametryn (SRA), trifloxysulfuron-sodium (SRT), ametryn+trifloxysulfuron-sodium (SRA+T), 2,4D (SR2,4-D) e sem herbicida (SRSH), aos 15, 30, 45 e 60 dias após aplicação dos herbicidas (DAA). Viçosa-MG, 2007

\begin{tabular}{|l|c|c|c|c|}
\hline \multirow{2}{*}{ Tratamento } & \multicolumn{5}{|c|}{ DAA } \\
\cline { 2 - 5 } & 15 & 30 & 45 & 60 \\
\hline \multicolumn{4}{|c|}{ Bactérias (log UFC $\mathrm{g}^{-1}$ de solo seco) CV parcela (\%) $=1,48$} \\
\hline SNRSH & $6,19 \mathrm{c}^{1 /}$ & $6,54 \mathrm{a}$ & $6,47 \mathrm{~b}$ & $6,30 \mathrm{c}$ \\
\hline SRSH & $6,51 \mathrm{a}$ & $6,60 \mathrm{a}$ & $6,68 \mathrm{a}$ & $6,66 \mathrm{a}$ \\
\hline SRA & $6,35 \mathrm{~b}$ & $6,47 \mathrm{a}$ & $6,23 \mathrm{c}$ & $6,50 \mathrm{~b}$ \\
\hline SRT & $6,54 \mathrm{a}$ & $6,45 \mathrm{a}$ & $6,62 \mathrm{a}$ & $6,49 \mathrm{~b}$ \\
\hline SRA+T & $6,59 \mathrm{a}$ & $6,37 \mathrm{~b}$ & $6,26 \mathrm{c}$ & $6,37 \mathrm{c}$ \\
\hline SR2,4-D & $6,32 \mathrm{~b}$ & $6,32 \mathrm{c}$ & $5,98 \mathrm{~d}$ & $6,37 \mathrm{c}$ \\
\hline \multicolumn{1}{|c|}{ Fungos (log UFC $\mathrm{g}^{-1} \mathrm{de}$ solo seco) CV parcela (\%) } & 2,08 \\
\hline SNRSH & $4,41 \mathrm{~d}$ & $4,96 \mathrm{~b}$ & $5,24 \mathrm{a}$ & $4,20 \mathrm{c}$ \\
\hline SRSH & $5,49 \mathrm{a}$ & $5,10 \mathrm{a}$ & $5,23 \mathrm{a}$ & $5,27 \mathrm{a}$ \\
\hline SRA & $5,11 \mathrm{c}$ & $5,19 \mathrm{a}$ & $5,29 \mathrm{a}$ & $5,15 \mathrm{~b}$ \\
\hline SRT & $5,27 \mathrm{~b}$ & $5,10 \mathrm{a}$ & $5,33 \mathrm{a}$ & $5,28 \mathrm{a}$ \\
\hline SRA+T & $5,31 \mathrm{~b}$ & $5,07 \mathrm{a}$ & $5,24 \mathrm{a}$ & $5,41 \mathrm{a}$ \\
\hline SR2,4-D & $5,01 \mathrm{c}$ & $5,07 \mathrm{a}$ & $5,29 \mathrm{a}$ & $5,35 \mathrm{a}$ \\
\hline
\end{tabular}

1/ Médias seguidas pela mesma letra na coluna e para cada grupo microbiano não diferem entre si pelo critério de Scott-Knott $(\mathrm{P}<0,05)$.

ação tóxica de aditivos na formulação comercial. Santos et al. (2004) também verificaram efeitos distintos de formulações comerciais de glyphosate sobre estirpes de bactérias fixadoras de nitrogênio da soja, sugerindo serem decorrentes da ação de aditivos nas formulações dos herbicidas.

Aos 15 DAA, os herbicidas 2,4-D e ametryn apresentaram as maiores reduções na densidade populacional fúngica do solo, análogas às observadas para densidade populacional bacteriana do solo, também aos 15 DAA (Tabela 2). Os fungos do solo mostraram-se, em geral, sensiveis a maiores concentrações dos herbicidas. Aos 30, 45 e 60 DAA, observou-se o restabelecimento da densidade populacional fúngica do solo, quer pelo ajuste metabólico das subpopulações afetadas pelos herbicidas ou pelo menor efeito das concentrações residuais dos herbicidas no solo.

Analisando o efeito dos herbicidas em cada época de avaliação (DAA), verificou-se que o 2,4-D e o trifloxysulfuron-sodium favoreceram 
maiores atividades de solubilização de fosfato inorgânico aos 15 e 30 DAA e aos 15, 30 e 45 DAA, respectivamente (Tabela 3 ), porém não afetaram a biomassa microbiana do solo (dados não mostrados). De acordo com Moorman (1989), os agrotóxicos pouco afetam a biomassa microbiana do solo, mas as populações e atividades de determinados grupos funcionais são afetadas.

Em razão da dose de trifloxysulfuron-sodium $\left(22,5 \mathrm{~g} \mathrm{ha}^{-1}\right)$ e de seu efeito na atividade dos MSFI, a ação bioestimulante e a alteração do padrão de exsudação radicular das plantas após a aplicação desse herbicida são sugeridas como mecanismo de aumento da solubilização de fosfato. Essa dose do trifloxysulfuron-sodium é insuficiente para promover o crescimento e/ou disponibilizar C e energia para atividade dos microrganismos. Em estudos de fisiologia vegetal, Shaw \& Burns (2004) sugerem que a alteração do padrão de exsudação radicular da planta na presença de herbicidas em sua rizosfera visa à estimulação dos microrganismos degradadores desses compostos. Esses mesmos autores constataram aumento na diversi- dade e quantidade de microrganismos degradadores de 2,4-D na rizosfera de Trifolium pratense após 25 dias da aplicação desse herbicida.

Aos 60 DAA, os tratamentos foram equivalentes quanto à atividade de solubilização de fosfato inorgânico em solo rizosférico (Tabela 3), indicando que as concentrações residuais dos herbicidas pouco afetaram a atividade dos microrganismos do solo. O 2,4-D é dissipado do solo em quatro a seis semanas após a aplicação, e o ametryn apresenta meiavida média de 60 dias (Silva et al., 2007). A meia-vida do trifloxysulfuron-sodium ainda não se encontra relatada na literatura.

Solos rizosféricos tratados com os herbicidas ametryn e trifloxysulfuron-sodium isolados apresentaram valores de solubilização relativa de fosfato inorgânico de, respectivamente, 4,80 e 4,45 $\mu \mathrm{g}$ Pi $\mu \mathrm{g}^{-1}$ CBM aos 30 DAA, e os tratados com mistura ametryn+trifloxysulfuronsodium, de 5,60 e 6,22 aos 30 e 45 DAA, respectivamente. Aos 15 e 60 DAA, não se observou diferença na solubilização relativa

Tabela 3 - Quantidade de fosfato inorgânico (Pi) liberado pela atividade de solubilização microbiológica de Ca $\left(\mathrm{PO}_{4}\right)_{2}$ e solubilização relativa de $\mathrm{Ca}_{3}\left(\mathrm{PO}_{4}\right)_{2}$ (quantidade de Pi liberado por unidade de carbono da biomassa microbiana) a partir de amostras de solo não-rizosférico sem aplicação de herbicida (SNRSH) e de solos rizosféricos tratados com ametryn (SRA), trifloxysulfuronsodium (SRT), ametryn+trifloxysulfuron-sodium (SRA+T), 2,4-D (SR2,4-D) e sem herbicida (SRSH), aos 15, 30, 45 e 60 dias após aplicação dos herbicidas (DAA). Viçosa-MG, 2007

\begin{tabular}{|c|c|c|c|c|}
\hline \multirow{2}{*}{ Tratamento } & \multicolumn{4}{|c|}{ DAA } \\
\hline & 15 & 30 & 45 & 60 \\
\hline \multicolumn{5}{|c|}{ Solubilização de fosfato inorgânico $\left(\mathrm{mg} \mathrm{L}^{-1}\right)-\mathrm{CV}$ parcela $=12,79 \%$} \\
\hline SNRSH & $36,61(85,83) b^{1 /}$ & $63,35(76,52) \mathrm{c}$ & $81,89(65,16) \mathrm{c}$ & $96,24(77,71) b$ \\
\hline SRSH & $42,65(100) b$ & $82,78(100) b$ & $125,66(100) \mathrm{b}$ & $123,83(100) \mathrm{a}$ \\
\hline SRA & $30,18(70,76) b$ & $104,10(125,75) \mathrm{a}$ & $124,41(99,00) b$ & $133,33(107,67) \mathrm{a}$ \\
\hline SRT & $72,97(171,09) \mathrm{a}$ & $120,55(145,62) \mathrm{a}$ & $148,91(118,50) \mathrm{a}$ & $143,36(115,77) \mathrm{a}$ \\
\hline $\mathrm{SRA}+\mathrm{T}$ & $28,22(66,16) b$ & $113,08(136,60) \mathrm{a}$ & $137,66(109,54) \mathrm{a}$ & $126,33(102,01) \mathrm{a}$ \\
\hline SR2,4-D & $57,93(135,89) \mathrm{a}$ & $98,68(119,20) \mathrm{a}$ & $114,16(90,84) b$ & $119,11(96,18) \mathrm{a}$ \\
\hline \multicolumn{5}{|c|}{ Solubilização relativa de fosfato inorgânico $\left(\mu \mathrm{g}\right.$ Pi $\left.\mu \mathrm{g}^{-1} \mathrm{CBM}\right)-\mathrm{CV}$ parcela $=30,51 \%$} \\
\hline SNRSH & $2,75(147,05) \mathrm{a}$ & $4,39(131,43) \mathrm{a}$ & $4,57(107,78) b$ & $3,99(126,66) \mathrm{a}$ \\
\hline SRSH & $1,87(100) \mathrm{a}$ & $3,34(100) b$ & $4,24(100) \mathrm{b}$ & $3,15(100) \mathrm{a}$ \\
\hline SRA & $1,69(90,37) \mathrm{a}$ & $4,45(133,23) \mathrm{a}$ & $4,78(112,73) b$ & $4,11(130,47) \mathrm{a}$ \\
\hline SRT & $2,88(154,01) \mathrm{a}$ & $4,80(143,71) \mathrm{a}$ & $5,06(119,33) \mathrm{b}$ & $3,97(126,03) \mathrm{a}$ \\
\hline $\mathrm{SRA}+\mathrm{T}$ & $1,74(93,04) \mathrm{a}$ & $5,60(167,66) \mathrm{a}$ & $6,22(146,69) \mathrm{a}$ & $4,27(135,55) \mathrm{a}$ \\
\hline SR2,4-D & $2,66(142,24) \mathrm{a}$ & $3,86(115,56) b$ & $3,60(84,90) b$ & $2,94(93,33) \mathrm{a}$ \\
\hline
\end{tabular}

Valores entre parênteses se referem à porcentagem em relação ao SRSH adotado como referência (100\%). ${ }^{1 /}$ Médias seguidas pela mesma letra na coluna não diferem entre si pelo critério de Scott-Knott $(\mathrm{P}<0,05)$. 
de fosfato inorgânico entre os tratamentos (Tabela 3).

Analisando o efeito tempo (DAA) na liberação de Pi pelos MSFI, os dados da atividade de solubilização e da solubilização relativa de fosfato inorgânico de todos os tratamentos se ajustaram aos modelos lineares de segunda ordem, isto é, com efeito quadrático (Figura 1).

Observou-se que o trifloxysulfuron-sodium estimulou a atividade dos MSFI (valor-p = 0,049) em todo o período de avaliação, com atividade máxima aos 54 DAA, obtida pela derivada primeira da equação ajustada para liberação de fosfato inorgânico (Figura 1). Em estudos que avaliam o efeito dos herbicidas oxadiazon e oxyfluorfen em MSFI, embora os fatores quantitativos não tenham sido analisados por regressão, verificou-se que a atividade máxima de liberação de Pi se encontra na faixa de 3060 DAA (Das et al., 2003). Comportamento semelhante foi observado por Debnath et al. (2002) em estudo que avaliou o impacto dos herbicidas butachlor e basalin na solubilização de fosfato inorgânico.

Para os modelos ajustados dos tratamentos ametryn, ametryn+trifloxysulfuron-sodium e 2,4-D em solos rizosféricos e a não-aplicação de herbicidas em solos não-rizosféricos, não

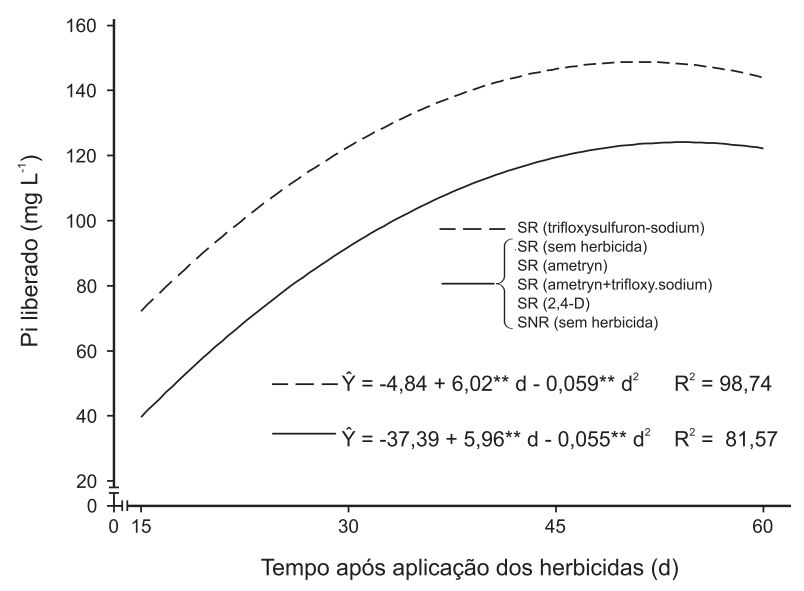

Figura 1 - Quantidade de fósforo inorgânico (Pi) liberado da solubilização de $\mathrm{Ca}_{3}\left(\mathrm{PO}_{4}\right)_{2}$ pelos microrganismos solubilizadores de fosfato do solo das amostras de solos tratados com ametryn, trifloxysulfuron-sodium, ametryn + trifloxysulfuron-sodium, 2,4-D e sem herbicida, aos 15, 30, 45 e 60 dias após aplicação dos herbicidas (DAA). SR= solo rizosférico e $\mathrm{SNR}=$ solo não-rizosférico ** significativo $(\mathrm{P}<0,01)$. Viçosa-MG, 2007. foram observadas diferenças em relação à testemunha, sendo ambos os modelos agrupados em uma única equação comum e com máxima solubilização aos 53,61 DAA (valor-p < 0,001) (Figura 1).

Contrariamente aos resultados obtidos na análise do efeito tempo na liberação de $\mathrm{Pi}$, a mistura ametryn+trifloxysulfuron-sodium apresentou-se mais impactante ao se analisar o efeito tempo na solubilização de Pi relativa (Figura 2). A maior liberação de Pi pode estar relacionada à acidificação do solo, em razão da maior produção de $\mathrm{CO}_{2}$ em solos tratados com herbicidas. Condições ácidas favorecem a solubilização de fosfatos insolúveis em água. Observou-se que a mistura ametryn+trifloxysulfuron-sodium propiciou maior produção de $\mathrm{CO}_{2}$ pelo solo dentre os herbicidas estudados (dados não mostrados). Taiwo \& Oso (1997) verificaram que em solos tratados com atrazine houve redução de quase uma unidade de $\mathrm{pH}$ no solo e, conseqüentemente, acréscimo de quase $5 \mathrm{mg} \mathrm{kg}^{-1}$ de Pi na solução do solo.

Com base nos resultados supramencionados, conclui-se que os herbicidas estudados interferiram na densidade populacional fúngica e bacteriana do solo, sendo o 2,4-D mais tóxico às bactérias do solo. A atividade dos MSFI

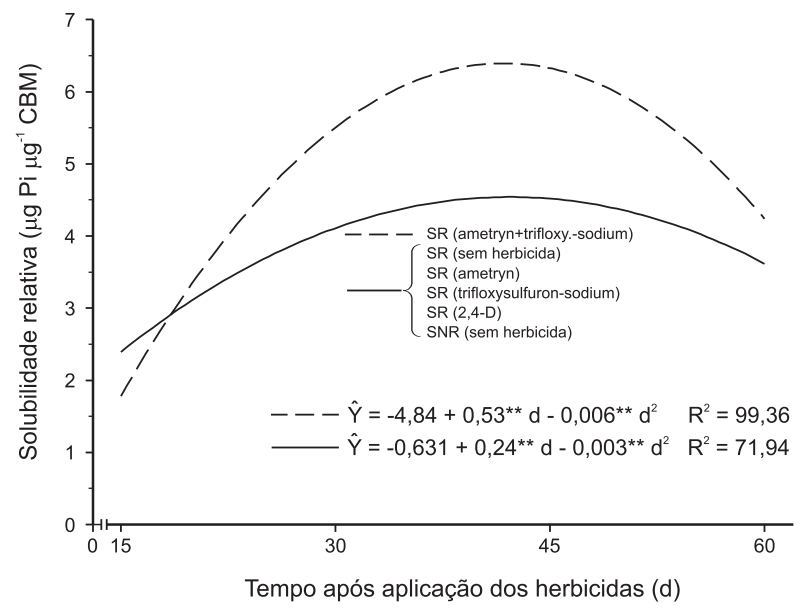

Figura 2 - Solubilização relativa de $\mathrm{Ca}_{3}\left(\mathrm{PO}_{4}\right)_{2}$ (quantidade de Pi liberado por unidade de biomassa microbiana) estimada das amostras de solos tratados com ametryn, trifloxysulfuron-sodium, ametryn + trifloxysulfuronsodium, 2,4-D e sem herbicida, 15, 30, 45 e 60 dias após aplicação dos herbicidas (DAA). SR= solo rizosférico e $\mathrm{SNR}=$ solo não-rizosférico. ${ }^{* *}$ significativo $(\mathrm{P}<0,01)$. Viçosa-MG, 2007

Planta Daninha, Viçosa-MG, v. 26, n. 2, p. 333-341, 2008 
não foi influenciada negativamente devido à aplicação dos herbicidas, sendo ainda estimulada na presença de trifloxysulfuron-sodium. A solubilização relativa de Pi foi favorecida pela mistura ametryn+trifloxysulfuron-sodium. Estudos microbiológicos envolvendo outros elementos importantes na dinâmica da microbiota do solo, como o C, $\mathrm{N}$ e S, podem contribuir para melhor entendimento dos efeitos adversos dos herbicidas no ambiente.

\section{AGRADECIMENTOS}

Ao Conselho Nacional de Desenvolvimento Científico e Tecnológico (CNPq), pelo apoio financeiro para a realização deste trabalho.

\section{LITERATURA CITADA}

BOTTOMLEY, P. J. Microbial ecology. In: SYLVIA, D. M. et al. Principles and applications of soil microbiology 2.ed. New Jersey: Upper Saddle River, 2005. p. 463-488.

BRAGA, J. M.; DEFELIPO, B. V. Determinação espectrofotométrica de fósforo em extratos de solos e plantas. Revista Ceres, v. 21, n. 113, p. 73-85, 1974.

CARNEIRO, R. G. et al. Indicadores biológicos associados ao ciclo do fósforo em solos de Cerrado sob plantio direto e plantio convencional. Pesq. Agropec. Bras., v. 39, n. 7, p. $661-669,2004$

CONGREGADO, F.; SIMON-PUJOL, D.; JUAREZ A. Effect of two organophosphorus insecticides on the phosphate-dissolving soil bacteria. Appl. Environ. Microbiol., v. 37, n. 1, p. 169-171, 1979.

DAS, A. C.; DEBNATH, A.; MUKHERJEE, D. Effect of the herbicides oxadiazon and oxyfluorfen on phosphates solubilizing microorganisms and their persistence in rice fields. Chemosphere, v. 53, p. 217-221, 2003.

DAS, A. C.; MUKHERJEE, D. Inseticidal effects on soil microorganisms and their biochemical processes related to soil fertility. World J. Microbiol. Biotechnol., v. 14, n. 6, p. 903-909, 1998.

DEBNATH, A.; DAS, A. C.; MUKHERJEE, D. Persistence and effect of butachlor and basalin on the activities of phosphate solubilizing microorganisms in wetland rice soil. Bull. Environ. Contam. Toxicol., v. 68, n. 5, p. 766-770, 2002.

ISLAM, K. R.; WEIL, R. R. Microwave irradiation of soil four routine measurement of microbial biomass carbon. Biol. Fert. Soils, v. 27, n. 4, p. 408-416, 1998.

Planta Daninha, Viçosa-MG, v. 26, n. 2, p. 333-341, 2008
KUCEY, R. M. N. Phosphate-solubilizing bacteria and fungi in various cultivated and virgin Alberta soils. Can. J. Soil. Sci., v.63, n. 4, p. 671-678, 1983.

LÓPEZ, L. et al. Studies on the effects of the inseticide aldrin on aquatic microbial populations. Int. Biodeter. Biodegrad., v. 50, n. 1, p. 83-87, 2002.

MARSCHNER, H. Mineral nutrition higher plants. 2.ed London: Academic Press, 1995. 889 p.

MARTIN, J. P. Use of acid, rose bengal, and estreptomycin in the plate method for estimating soil fungi. Soil. Sci., v. 69, n. 2 , p. $215-232,1950$.

MOORMAN, T. B. A review of pesticide effects on microorganisms and microbial processes related to soil fertility. J. Crop. Prod., v. 2, p. 14-23, 1989.

NAHAS, E.; CENTURION, J. F.; ASSIS, L. C. Microrganismos solubilizadores de fosfato e produtores de fosfatases de vários solos. R. Bras. Ci. Solo, v. 18, n. 1, p. 43-48, 1994.

NAUTIYAL, C. S. An efficient microbiological growth medium for screening phosphate solubilizing microorganisms. FEMS Microbiol. Letters, v. 170, n. 1, p. $265-270,1999$.

NOVAIS, R. F.; SMYTH, T. J. (Eds.). Fósforo em solo e planta em condições tropicais. Viçosa, MG: Universidade Federal de Viçosa, 1999. 399 p.

PANKHURST, C. E.; DOUBE, B. M.; GUPTA, V. V. S. R. (Eds.). Biological indicators of soil health. Boca Raton: CRC Press, 1997. 268 p.

REGAZZI, A. J. Teste para verificar a igualdade de modelos de regressão e a igualdade de alguns parâmetros num modelo polinomial ortogonal. R. Ceres, v. 40, n. 228, p. 176-195, 1993.

RODRÍGUEZ, H.; FRAGA, R. Phosphate solubilizing bacteria and their role in plant growth promotion. Biotechnol. Adv., v. 17, n. 4-5, p. 319-339, 1999.

ROSAS, S. B. et al. Phosphate-solubilizing Pseudomonas putida can influence the rizobia-legume symbiosis. Soil Biol. Biochem., v. 38, n. 12, p. 3502-3505, 2006.

SANTOS, J. B. et al. Efeitos de diferentes formulações comerciais de glyphosate sobre estirpes de Bradyrhizobium. Planta Daninha, v. 22, n. 2, p. 293-299, 2004

SELVAMANI, S.; SANKARAN, S. Soil microbial population as affected by herbicides. Madras Agric. J., v. 80, p. 397-399, 1993. 
SHAW, L. J.; BURNS, R. G. Enhanced mineralization of [U$\left.{ }^{14} \mathrm{C}\right]$ 2,4-dichlorophenoxy- acetic acid in soil from the rhizosphere of Trifolium pretense. Appl. Environ.

Microbiol., v. 70, n. 8, p. 4766-4774, 2004

SILVA, A. A. et al. Herbicidas: classificação e mecanismo de ação. In: SILVA, A. A.; SILVA, J. F. (Eds.). Tópicos em manejo de plantas daninhas. Viçosa, MG: Universidade Federal de Viçosa, 2007. 367 p.

TAIWO, L. B.; OSO, B. A. The influence of some pesticides on soil microbial flora in relation to changes in nutrient level, rock phosphate solubilization and $\mathrm{P}$ release under laboratory conditions. Agric. Ecosys. Environ., v. 65, n. 1, p. 59-68, 1997.
THILL, D. Growth regulator herbicides. In: Herbicide action course. West Lafayette: Purdue University, 2003. p. 267-291.

TÓTOLA, M. R.; CHAER, G. M. Microrganismos e processos microbiológicos como indicadores da qualidade dos solos. In: VENEGAS, V. H. A. et al. (Eds.). Tópicos em Ciência do Solo. Viçosa, MG: Sociedade Brasileira de Ciência do Solo, 2002. v. 2. p. 195-276.

VANCE, E. D.; BROOKES, P. C.; JENKINSON, D. S. An extraction method for measuring soil microbial biomass $\mathrm{C}$. Soil. Biol. Biochem., v. 19, n. 6, p. 703-707, 1987.

WALKER, T. S. et al. Root exudation and rhizosphere biology. Plant Physiol., v. 132, n. 1, p. 44-51, 2003. 